\title{
Relation of Apolipoprotein E Polymorphism to Markers of Early Atherosclerotic Changes in Young Adults The Cardiovascular Risk in Young Finns Study
}

\author{
Paula Grönroos, MD, $\mathrm{PhD}^{*}$,**; Olli T. Raitakari, $\mathrm{MD}, \mathrm{PhD}^{\dagger}$; Mika Kähönen, $\mathrm{MD}, \mathrm{PhD}^{\dagger \dagger}$; \\ Nina Hutri-Kähönen, MD, PhD*; Markus Juonala, MD, PhD\$; Jukka Marniemi, $\mathrm{PhD}^{\S}$; \\ Jorma Viikari, MD, $\mathrm{PhD} \$$; Terho Lehtimäki, MD, $\mathrm{PhD}^{* *}$
}

\begin{abstract}
Background Carotid artery intima-media thickness (IMT), which is measured by ultrasound, is used in the assessment of early atherosclerotic changes, and has been associated with apolipoprotein E (APOE) polymorphism in many studies comprising elderly subjects. However, results are still inconclusive and data relating to young adults are missing. Whether common APOE polymorphism is related to carotid IMT was studied in a population of young adults. Also brachial flow-mediated dilatation (FMD) and carotid artery compliance (CAC) were determined to clarify their relation to this genetic factor.

Methods and Results A total of 1,188 young adults (aged 24-39 years) participating in the Cardiovascular Risk in Young Finns Study with complete data of common APOE polymorphism underwent a carotid and brachial ultrasound. Patients' lipid levels and blood pressure were also examined. There was no significant association between the APOE phenotypes and carotid IMT, brachial FMD or CAC either in young men or in young women. The results were similar for systolic and diastolic blood pressure. In the same population, the well-known association between APOE phenotypes and lipids was seen.

Conclusions Common APOE polymorphism does not seem to be an independent genetic determinant of carotid IMT, brachial FMD or CAC. (Circ J 2008; 72: 29-34)
\end{abstract}

Key Words: Apolipoproteins E; Atherosclerosis; Carotid arteries; Cholesterol; Genetic polymorphism

$\mathbf{U}$ ltrasonic methods, such as measurements of carotid artery intima-media thickness (IMT), carotid artery compliance (CAC) and brachial artery flow-mediated dilatation (FMD), have gained increasing acceptance in the assessment of early atherosclerotic changes. Especially, carotid IMT is widely used as a measure of subclinical atherosclerosis, but brachial FMD responses also predict future cardiovascular events in patient groups and decreased arterial elasticity has been implicated as an independent predictor of cardiovascular events and mortality in high-risk individuals!-6 Convential cardiovascular risk factors (eg, high low-density lipoprotein (LDL)-cholesterol), in turn, have been associated with increased carotid IMT, decreased brachial FMD and decreased arterial elasticity!,7-13

(Received February 27, 2007; revised manuscript received August 24, 2007; accepted September 3, 2007)

*Department of Clinical Chemistry, University of Turku, Turku, **Laboratory of Atherosclerosis Genetics, Department of Clinical Chemistry, Tampere University Hospital and the Medical School at the University of Tampere, Tampere, ${ }^{\dagger}$ Department of Clinical Physiology, University of Turku, Turku, "Department of Clinical Physiology, Department of Paediatrics, Tampere University Hospital, Tampere, \#Research Centre of Applied and Preventive Cardiovascular Medicine, University of Turku, §Department of Health and Functional Capacity, Population Research Laboratory, National Public Health Institute and $\$$ Department of Medicine, University of Turku, Turku, Finland

Mailing address: Paula Grönroos, MD, PhD, Department of Clinical Chemistry, University of Turku, Kiinamyllynkatu 4-8, PO Box 52, FIN-20521 Turku, Finland. E-mail: paula.gronroos@tyks.fi All rights are reserved to the Japanese Circulation Society. For permissions, please e-mail: cj@j-circ.or.jp
Genetic factors play a role in the pathogenesis of atherosclerosis, partly by influencing plasma lipoprotein concentrations, ${ }^{4}, 14-18$ Heritability estimates of interindividual differences in IMT range from $30 \%$ to $40 \%$ but the specific genes contributing to this variability are unknown $4,19,20$ Of the many candidate genes investigated for their possible influence on the risk of coronary artery disease, the gene for apolipoprotein E (APOE) has received much attention ${ }^{4}$ and APOE polymorphism, in general, is considered an important genetic determinant and risk factor for coronary heart disease $^{21,22}$ Genetic variation in the polymorphic APOE locus significantly affects plasma lipoprotein concentrations ${ }^{17,19,20,23}$ but the effects on IMT, FMD or CAC are inadequately known. Several studies have examined the APOE gene with respect to carotid IMT but results have been inconclusive ${ }^{24,25} \mathrm{An}$ association between the $\epsilon 4$ allele and higher IMT or the $\epsilon 2$ allele and lower IMT has been found in some, but not all, studies!6,26-34 Subjects in most previous studies have been middle-aged or older or have represented diverse patient groups. Furthermore, very little is known about whether the APOE locus affects interindividual variation of brachial FMD or CAC 35,36

Therefore, we examined the relation of common APOE polymorphism to carotid IMT, brachial FMD and CAC in 1,188 young adults (aged $24-39$ years) participating in the Cardiovascular Risk In Young Finns Study. In the same population, the lipid and lipoprotein levels as well as blood pressure were examined according to the APOE phenotypes. 


\section{Methods}

\section{Subjects}

The Cardiovascular Risk in Young Finns Study is an ongoing multicentre follow-up study of atherosclerosis risk factors in Finnish children and adolescents ${ }^{17}$ The baseline study was conducted in 1980 and the follow-up studies in 1983, 1986 and 2001. The baseline study included 3,596 boys and girls in the age groups of 3, 6, 9, 12, 15 and 18 years. The subjects were randomly chosen from the national population register from the areas of 5 university cities in Finland (ie, Helsinki, Kuopio, Oulu, Tampere and Turku) and from rural municipalities in their vicinity. Details of the study design have been presented elsewhere 37 The APOE phenotype analyses were carried out in 1,736 boys and girls, who represented a random subsample of the children and adolescents participating in the 1986 followup study, with approximately an equal number of boys and girls in each of the 6 age groups 17 Carotid IMT and CAC were measured by ultrasonography in 2,265 subjects and FMD in 2,109 subjects (aged 24-39 years) participating in the latest follow-up study. Subjects with data of both APOE phenotype and ultrasonography $(n=1,188)$, as well as APOE phenotype and lipids $(n=1,233)$, were included in the present analysis.

Subjects gave written informed consent and the study was approved by the local ethics committees of the participating universities.

\section{Physical Examination}

Weight was measured in light clothing without shoes, using a digital scale with an accuracy of $0.1 \mathrm{~kg}$, and height was measured by a wall-mounted statiometer with $0.5 \mathrm{~cm}$ accuracy. Body mass index (BMI) was calculated from the formula $\mathrm{BMI}=$ weight $(\mathrm{kg}) /[\text { height }(\mathrm{m})]^{2}$. Blood pressure was measured with a random zero sphygmomanometer. Korotkoff's fifth sound was used as the sign for diastolic blood pressure and first sound as the sign for systolic blood pressure. Readings to the nearest even number of millimeters of mercury were performed at least 3 times on each subject. The average of these measurements was used in the analysis.

\section{Ultrasound Studies}

Ultrasound studies were performed using Sequoia 512 ultrasound mainframes (Acuson, CA, USA) with a $13.0 \mathrm{MHz}$ linear array transducer, as described elsewhere 38 To assess intra-individual reproducibility of ultrasound measurements, 57 subjects were re-examined 3 months after the initial visit (2.5\% random sample).

To measure carotid IMT the image was focused on the posterior (far) wall of the left carotid artery 38,39 A magnified image was recorded from an angle that showed the greatest distance between the lumen-intima interface and the media-adventitia interface. A minimum of 4 measurements of the common carotid far wall was taken, approximately $10 \mathrm{~mm}$ proximal to the bifurcation, to derive mean and maximal carotid IMT. The between-visit coefficient of variation $(\mathrm{CV})$ of IMT measurements was $6.4 \%$.

To assess CAC indices, the left carotid artery was scanned by physicians and ultrasound technicians following standard protocol! ${ }^{12}$ In brief, several 5-s moving image clips of the beginning of the carotid bifurcation and the common carotid artery were acquired and stored. From the 5-s clips, the best quality cardiac cycle was selected and manually analyzed by a single reader blinded to the subjects' details. The analyses were performed using ultrasonic callipers. The carotid diameter was measured at least twice in the end-diastole and end-systole, respectively. The mean of the measurements was used as the end-diastolic or end-systolic diameter. Ultrasound and concomitant brachial blood pressure measurements were used to calculate CAC [\%/10 mmHg] with the equation $\left(\left[\mathrm{D}_{\mathrm{s}}-\mathrm{D}_{\mathrm{d}}\right] / \mathrm{D}_{\mathrm{d}}\right) /\left(\mathrm{P}_{\mathrm{s}}-\mathrm{P}_{\mathrm{d}}\right)$, whereby $\mathrm{D}_{\mathrm{d}}$ is the diastolic diameter, Ds is the systolic diameter, Ps is systolic blood pressure and $\mathrm{Pd}_{\mathrm{d}}$ is diastolic blood pressure. The between-visit $\mathrm{CV}$ for the end-diastolic carotid diameter was $2.7 \%$ and was $13.1 \%$ for carotid diameter change.

To assess brachial artery FMD, the left brachial artery diameter was measured both at rest and during reactive hyperemia, as described elsewhere ${ }^{39}$ In short, increased flow was induced by inflating a pneumatic tourniquet placed around the forearm to a pressure of $250 \mathrm{mmHg}$ for $4.5 \mathrm{~min}$, followed by release. Three measurements of arterial diameter were performed at end-diastole at a fixed distance from an anatomic marker at rest, as well as 40, 60 and 80 s after cuff release. The vessel diameter in scans after reactive hyperemia was expressed as a percentage relative to the resting scan $(100 \%)$. The average of 3 measurements at each time point was used to derive the maximum FMD (ie, the greatest value between 40 and $80 \mathrm{~s}$ ). The between-visit $\mathrm{CV}$ for brachial diameter was $3.2 \%$ and for FMD was $26.0 \%$. The intra-observer CV was $1.2 \%$ for brachial diameter and was $15.3 \%$ for FMD.

\section{APOE Phenotyping}

APOE phenotyping was performed using delipidated plasma, isoelectric focusing, cysteamine treatment and immunoblotting, as described by Menzel and Utermann, ${ }^{40}$ with minor modifications described by Lehtimäki et al17 The verification of correct APOE phenotypes in gel was based on a comparison to previously known APOE genotype standards.

\section{Analysis of Lipids}

The analyses of lipids were performed in the laboratory of the Research and Development Unit of the Social Insurance Institution, Turku, Finland. Serum cholesterol and triglyceride concentrations were determined enzymatically (Olympus System Reagent; Olympus Diagnostica $\mathrm{GmbH}$, Hamburg, Germany) using a clinical chemistry analyzer (AU400; Olympus Optical Ltd, Mishima, Japan). High-density lipoprotein (HDL)-cholesterol was analyzed after precipitation of very LDL and LDL-with dextrane sulfate 500,00041 The concentration of LDL-cholesterol was calculated using the formula of Friedewald and colleagues. ${ }^{42}$ Subjects with triglycerides $>4 \mathrm{mmol} / \mathrm{L}(\mathrm{n}=16)$ were excluded from this analysis. Inter-assay CV was $2.19 \%$ for serum cholesterol, $2.28 \%$ for HDL-cholesterol and $3.76 \%$ for serum triglycerides.

\section{Statistical Analysis}

Statistical analysis was performed using the SPSS 13.0 for Windows (SPSS Inc, Chicago, IL, USA) on microcomputer.

The levels of lipids in different APOE phenotypes were compared using one-way analysis of variance. The levels of IMT, FMD, CAC and blood pressure in different APOE phenotypes were compared using one-way analysis of covariance (ANCOVA) adjusted for BMI and age. Both analyses were performed for the total population and separately for each gender. In the analysis for each gender, one male subject representing the homozygous APOE $\in 2 \notin 2$ 
Table 1 Serum Lipids in Young Adults (24-39 Years) According to Apolipoprotein E Phenotypes Values are the Mean \pm SD

\begin{tabular}{|c|c|c|c|c|c|c|c|c|}
\hline & \multicolumn{6}{|c|}{ Apolipoprotein E phenotype } & \multirow{2}{*}{ Total } & \multirow{2}{*}{$p$ value ${ }^{a}$} \\
\hline & $E 2 / 2$ & $E 3 / 2$ & $E 4 / 2$ & $E 3 / 3$ & $E 4 / 3$ & $E 4 / 4$ & & \\
\hline \multicolumn{9}{|l|}{$N$} \\
\hline$F$ & 3 & 41 & 13 & 396 & 205 & 24 & 682 & \\
\hline$M$ & $1^{b}$ & 24 & 12 & 321 & 173 & 20 & 551 & \\
\hline All & 4 & 65 & 25 & 717 & 378 & 44 & 1,233 & \\
\hline \multicolumn{9}{|c|}{$T C(\mathrm{mmol} / \mathrm{L})$} \\
\hline$F$ & $4.20 \pm 0.50$ & $4.49 \pm 0.59$ & $5.33 \pm 0.97$ & $5.01 \pm 0.93$ & $5.20 \pm 0.94$ & $5.30 \pm 1.17$ & $5.05 \pm 0.94$ & $<0.001$ \\
\hline$M$ & 4.70 & $4.28 \pm 0.92$ & $4.97 \pm 1.08$ & $5.19 \pm 1.03$ & $5.27 \pm 0.96$ & $5.53 \pm 1.15$ & $5.18 \pm 1.03$ & $<0.001$ \\
\hline All & $4.33 \pm 0.48$ & $4.41 \pm 0.73$ & $5.16 \pm 1.02$ & $5.09 \pm 0.98$ & $5.23 \pm 0.95$ & $5.41 \pm 1.15$ & $5.11 \pm 0.98$ & $<0.001$ \\
\hline \multicolumn{9}{|c|}{$L D L-C(\mathrm{mmol} / \mathrm{L})$} \\
\hline$F^{c}$ & $2.06 \pm 0.06$ & $2.44 \pm 0.45$ & $3.24 \pm 0.80$ & $3.11 \pm 0.76$ & $3.34 \pm 0.78$ & $3.22 \pm 0.80$ & $3.14 \pm 0.78$ & $<0.001$ \\
\hline$M^{d}$ & 2.50 & $2.62 \pm 0.83$ & $3.08 \pm 0.86$ & $3.37 \pm 0.90$ & $3.48 \pm 0.86$ & $3.66 \pm 1.07$ & $3.38 \pm 0.90$ & $<0.001$ \\
\hline Alle & $2.17 \pm 0.22$ & $2.50 \pm 0.62$ & $3.16 \pm 0.81$ & $3.23 \pm 0.83$ & $3.40 \pm 0.82$ & $3.40 \pm 0.94$ & $3.24 \pm 0.85$ & $<0.001$ \\
\hline \multicolumn{9}{|c|}{$H D L-C(\mathrm{mmol} / \mathrm{L})$} \\
\hline$F$ & $1.51 \pm 0.53$ & $1.50 \pm 0.30$ & $1.35 \pm 0.27$ & $1.39 \pm 0.30$ & $1.36 \pm 0.29$ & $1.56 \pm 0.40$ & $1.39 \pm 0.30$ & 0.007 \\
\hline$M$ & 1.20 & $1.07 \pm 0.23$ & $1.29 \pm 0.25$ & $1.18 \pm 0.27$ & $1.11 \pm 0.26$ & $1.04 \pm 0.24$ & $1.15 \pm 0.27$ & 0.003 \\
\hline All & $1.44 \pm 0.46$ & $1.34 \pm 0.33$ & $1.32 \pm 0.26$ & $1.29 \pm 0.30$ & $1.24 \pm 0.31$ & $1.32 \pm 0.42$ & $1.28 \pm 0.31$ & 0.043 \\
\hline \multicolumn{9}{|c|}{$T G(\mathrm{mmol} / \mathrm{L})$} \\
\hline$F$ & $1.37 \pm 0.55$ & $1.23 \pm 0.66$ & $2.38 \pm 3.30$ & $1.13 \pm 0.55$ & $1.14 \pm 0.55$ & $1.19 \pm 0.63$ & $1.16 \pm 0.73$ & 0.024 \\
\hline$M$ & 2.30 & $1.30 \pm 0.52$ & $1.33 \pm 0.76$ & $1.45 \pm 0.96$ & $1.58 \pm 0.88$ & $1.87 \pm 1.41$ & $1.50 \pm 0.94$ & 0.074 \\
\hline All & $1.60 \pm 0.65$ & $1.25 \pm 0.61$ & $1.88 \pm 2.45$ & $1.27 \pm 0.78$ & $1.34 \pm 0.75$ & $1.49 \pm 1.10$ & $1.31 \pm 0.84$ & 0.066 \\
\hline
\end{tabular}

SD, standard deviation; $N$, number of subjects; F, females; $M$, males; $T C$, total cholesterol; LDL-C, low-density lipoprotein-cholesterol; HDL-C, high-density lipoprotein-cholesterol; $T G$, triglycerides.

${ }^{a} P$ values obtained from one-way analysis of variance. ${ }^{b}$ Excluded from statistical analysis. ${ }^{c} 3$ values excluded. ${ }^{d} 13$ values excluded. ${ }^{e} 16$ values excluded, serum triglycerides $>4 \mathrm{mmol} / \mathrm{L}$.

Table 2 Maximal IMT, Mean IMT, Maximal FMD, CAC, Systolic RR and Diastolic RR in Young Adults (24-39 Years) According to Apolipoprotein E Phenotypes Values are the Mean \pm SD

\begin{tabular}{|c|c|c|c|c|c|c|c|c|}
\hline & \multicolumn{6}{|c|}{ Apolipoprotein E phenotype } & \multirow{2}{*}{ Total } & \multirow{2}{*}{$p$ value } \\
\hline & $E 2 / 2$ & $E 3 / 2$ & $E 4 / 2$ & $E 3 / 3$ & $E 4 / 3$ & $E 4 / 4$ & & \\
\hline \multicolumn{9}{|c|}{ Maximal IMT $(\mathrm{mm})(\mathrm{N})$} \\
\hline$F$ & $0.57 \pm 0.12$ & $0.61 \pm 0.08(39)$ & $0.63 \pm 0.13(11)$ & $0.61 \pm 0.09(382)$ & $0.60 \pm 0.09(196)$ & $0.62 \pm 0.12(24)$ & $0.61 \pm 0.09(655)$ & 0.928 \\
\hline$M$ & $0.42\left(1^{b}\right)$ & $0.62 \pm 0.11$ & $0.58 \pm 0.08(12)$ & $0.63 \pm 0.10(307)$ & $0.63 \pm 0.09(169)$ & $0.61 \pm 0.11(20)$ & $0.63 \pm 0.10(533)$ & 0.346 \\
\hline All & $0.53 \pm 0.13(4)$ & $0.61 \pm 0.09(63)$ & $0.60 \pm 0.10(23)$ & $0.62 \pm 0.09(689)$ & $0.61 \pm 0.09(365)$ & $0.61 \pm 0.11(44)$ & $0.62 \pm 0.09(1,188)$ & 0.669 \\
\hline \multicolumn{9}{|c|}{ ( } \\
\hline$F$ & $0.53 \pm 0.10$ & $0.57 \pm 0.08$ & $0.58 \pm 0.11(11)$ & $0.57 \pm 0.08$ & $0.56 \pm 0.08(196)$ & $0.57 \pm 0.11(24)$ & $0.56 \pm 0.08(655)$ & 0.867 \\
\hline$M$ & $0.42\left(1^{b}\right)$ & $0.58 \pm 0.10(24)$ & $0.53 \pm 0.07(12)$ & $0.59 \pm 0.10$ & $0.59 \pm 0.09(169)$ & $0.57 \pm 0.10(20)$ & $0.58 \pm 0.10(533)$ & 0.316 \\
\hline All & $0.50 \pm 0.10$ & $0.57 \pm 0.08(63)$ & $0.55 \pm 0.10(23)$ & $0.58 \pm 0.09(689)$ & $0.57 \pm 0.09(365)$ & $0.57 \pm 0.10(44)$ & $0.57 \pm 0.09(1,188)$ & 0.662 \\
\hline \multicolumn{9}{|c|}{ 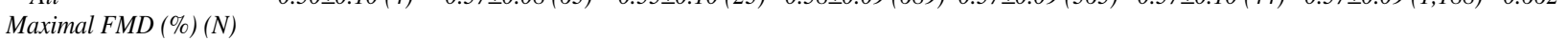 } \\
\hline$F$ & $3.54 \pm 2.81(2)$ & $8.85 \pm 5.36(37)$ & $11.31 \pm 4.95(11)$ & $8.96 \pm 4.35(365)$ & $9.36 \pm 4.76(187)$ & $9.27 \pm 3.87(22)$ & $9.11 \pm 4.54(624)$ & 0.324 \\
\hline$M$ & $2.76\left(1^{b}\right)$ & $7.77 \pm 5.17(22)$ & $6.26 \pm 3.63(11)$ & $7.30 \pm 4.05(282)$ & $6.62 \pm 3.99(154)$ & $7.03 \pm 4.37(19)$ & $7.07 \pm 4.09(489)$ & 0.491 \\
\hline All & $3.28 \pm 2.04(3)$ & $8.45 \pm 5.27(59)$ & $8.79 \pm 4.96(22)$ & $8.23 \pm 4.29(647)$ & $8.12 \pm 4.63(341)$ & $8.23 \pm 4.21(41)$ & $8.21 \pm 4.46(1,113)$ & 0.485 \\
\hline \multicolumn{9}{|c|}{ CAC $(\% / 10 \mathrm{mmHg})(\mathrm{N})$} \\
\hline$F$ & $2.80 \pm 0.77$ & $2.36 \pm 0.74(39)$ & $2.61 \pm 0.95(11)$ & $2.38 \pm 0.79(380)$ & $2.27 \pm 0.75(196)$ & $2.16 \pm 0.95$ & $2.34 \pm 0.79(653)$ & 0.235 \\
\hline$M$ & $0.87\left(1^{b}\right)$ & $2.06 \pm 0.71(24)$ & $1.96 \pm 0.50(11)$ & $2.04 \pm 0.64(306)$ & $2.04 \pm 0.68(168)$ & $2.11 \pm 0.43(20)$ & $2.04 \pm 0.65(530)$ & 0.734 \\
\hline All & $2.32 \pm 1.15$ & $2.25 \pm 0.74$ & $2.28 \pm 0.81(22)$ & $2.23 \pm 0.75(686)$ & $2.16 \pm 0.73(364)$ & $2.14 \pm 0.75(44)$ & $2.21 \pm 0.74(1,183)$ & 0.585 \\
\hline \multicolumn{9}{|c|}{ Systolic RR $(\mathrm{mmHg})(\mathrm{N})$} \\
\hline$F$ & $108 \pm 6(3)$ & $116 \pm 14(39)$ & $114 \pm 14(11)$ & $115 \pm 11(380)$ & $117 \pm 13(197)$ & $116 \pm 9(24)$ & $116 \pm 12(654)$ & 0.450 \\
\hline$M$ & $161\left(1^{b}\right)$ & $130 \pm 12(24)$ & $125 \pm 11(11)$ & $129 \pm 13(306)$ & $130 \pm 12(170)$ & $128 \pm 12(20)$ & $129 \pm 12(532)$ & 0.886 \\
\hline All & $121 \pm 27(4)$ & $121 \pm 15(63)$ & $120 \pm 13(22)$ & $122 \pm 14(686)$ & $123 \pm 14$ & $122 \pm 12(44)$ & $122 \pm 14(1,186)$ & 0.506 \\
\hline \multicolumn{9}{|c|}{ Diastolic $R R(m m H g)(N)$} \\
\hline$F$ & $59 \pm 6(3)$ & $72 \pm 10(39)$ & $69 \pm 7(11)$ & $71 \pm 8(380)$ & $72 \pm 9(197)$ & $73 \pm 7(24)$ & $72 \pm 8(654)$ & 0.087 \\
\hline$M$ & $89\left(1^{b}\right)$ & $74 \pm 7(24)$ & $74 \pm 7(11)$ & $75 \pm 9(306)$ & $75 \pm 8(170)$ & $74 \pm 8(20)$ & $75 \pm 8(532)$ & 0.980 \\
\hline All & $66 \pm 16(4)$ & $73 \pm 9(63)$ & $71 \pm 7(22)$ & $73 \pm 9(686)$ & $74 \pm 9(367)$ & $74 \pm 8(44)$ & $73 \pm 9(1,186)$ & 0.400 \\
\hline
\end{tabular}

IMT, intima-media thickness; FMD, flow-mediated dilatation; CAC, carotid artery compliance; RR, blood pressure. Other abbreviations see in Table 1.

${ }^{a} P$ values obtained from one-way analysis of covariance adjusted for body mass index and age. ${ }^{b}$ Excluded from statistical analysis.

phenotype was excluded from statistical analysis because he was the only representative of this group and for having abnormal patient characteristics $\left(B M I=45.8 \mathrm{~kg} / \mathrm{m}^{2}\right)$. His values are, however, shown in the Tables 1 and 2.

In order to examine the effects of the $\epsilon 4$ and $\epsilon 2$ alleles, the population was divided into the groups: E4 $(\epsilon 3 / 4$ and $\in 4 / 4)$; E2 $(\epsilon 2 / 2$ and $\epsilon 3 / 2)$; and E3 $(\in 3 \notin 3)$, and the groups were compared using one-way ANCOVA adjusted for BMI and age.

Values for serum triglycerides were $\log 10$-transformed prior to statistical analyses because of skewed distribution. Values without $\log 10$-transformation are shown in Tables 1 and 2. 


\section{Results}

The relative frequencies of the $\epsilon 2, \epsilon 3$ and $€ 4$ alleles in the study population were $\epsilon 2=0.04, \epsilon 3=0.76$ and $\epsilon 4=0.20$. These were similar to those found earlier in the Cardiovascular Risk in Young Finns Study $(\epsilon 2=0.04, \epsilon 3=0.77$ and $\epsilon 4=0.19))^{17}$

There were significant differences between the APOE phenotype groups in serum total cholesterol $(\mathrm{p}<0.001)$, LDL-cholesterol $(\mathrm{p}<0.001)$ and HDL-cholesterol $(\mathrm{p}=0.007$ for women, $\mathrm{p}=0.003$ for men) in both genders. In females, there was also a statistically significant difference for triglycerides $(\mathrm{p}=0.024$ for women $)$ between the APOE phenotype groups (Table 1).

However, there were no significant differences in the ultrasound markers of early atherosclerotic changes in the different APOE phenotype groups. None of the parameters maximal IMT $(p=0.669)$, mean IMT $(p=0.662)$, maximal FMD $(p=0.485)$ or CAC $(p=0.585)$ were associated with APOE phenotype in one-way ANCOVA adjusted for BMI and age (Table 2). The analysis was also performed for each gender separately but no significant differences were found. The results were similar for systolic and diastolic blood pressure.

Furthermore, when the study population was divided into groups; that is, E4 group $(\epsilon 3 / 4$ and $\epsilon 4 / 4)$, E2 group $(\epsilon 2 / 2$ and $\epsilon 3 / 2$ ) and $E 3$ group $(\epsilon 3 / 3)$, there were no significant differences in maximal IMT $(\mathrm{p}=0.972)$, mean IMT $(\mathrm{p}=0.803)$, maximal FMD $(p=0.958)$, CAC $(p=0.173)$ or systolic $(p=$ $0.192)$ and diastolic blood pressure $(p=0.490)$ either for the whole population or for each gender. If the APOE 4/2 phenotype carrying both the $\epsilon$ and $€ 2$ alleles was included either in the E4 or E2 group, the results remained similar for the whole population and for each gender.

\section{Discussion}

We found that common APOE polymorphism is not associated with carotid IMT, brachial FMD or CAC in young adults. The analyses were performed for each gender but no association was observed. Dividing the population into groups; that is, E4 group $(\epsilon 3 / 4$ and $\epsilon 4 / 4)$, E2 group $(\epsilon 2 / 2$ and $\epsilon 3 / 2)$ and $E 3$ group $(\epsilon 3 / 3)$, did not change the results. However, the well-known link between APOE phenotypes and serum lipids was seen in the same population.

The relationship between APOE polymorphism and carotid IMT has been extensively studied but the results have been discordant. A review by Humphries and Morgan concluded that the APOE gene seems to determine the variability of IMT, as many studies have shown an association between the $\epsilon 4$ allele and higher IMT. However, subjects in most positive studies have been middle-aged or older, or have represented patient groups with coronary artery disease or diabetes, or have comprised only men. ${ }^{26-32}$ The Framingham Heart Study found that common carotid artery IMT in the APOE 2 group (including $\epsilon 2 / 2$ and $\epsilon 3 / 2$ genotypes) was lower than that in the APOE $4(\epsilon 4 / 3$ and $\epsilon 4 / 4)$ and APOE $3(\epsilon 3 / 3)$ groups in women. However, when plasma lipids were included in the statistical model, the association was no longer statistically significant. Also, in a recent American study by Volcik and coworkers, they found that the association of APOE $\epsilon 2$ and $\epsilon 4$ alleles with carotid IMT in an elderly population disappeared after adjusting for lipid parameters in Caucasians, but for African Americans, they found that the $\epsilon$ allele association remained after ad- justing for lipid parameters 33 These alleles did not predict the incidence of coronary heart disease in either racial group, but in a smaller population of subjects under 65 years, the $\epsilon 4$ allele was a significant predictor of early coronary heart disease. Recently, Debette and coworkers demonstrated in the elderly (aged $\geq 65$ years) that the frequency of carotid plaques was significantly higher in $\epsilon 4$ homozygotes and lower in $€ 2$ carriers compared with $\in 3$ homozygotes, but the association was independent of lipid levels ${ }^{34}$ They also found a marginal association between APOE $\epsilon$ 3/4 and IMT but it disappeared after excluding subjects with carotid plaques ${ }^{34}$ The relationship between brachial FMD and APOE polymorphism has been studied in 96 asymptomatic Japanese male subjects aged $50 \pm 8$ years by Haraki and coworkers, whereby no association was found 35 Furthermore, a recent study by Viiri and coworkers found no significant association between the APOE promoter genotypes and carotid IMT, brachial FMD or CAC within the APOE $\in 3 k 3$ carriers 36

The present study differs from that of previous studies in that we examined the association between common APOE polymorphism and carotid IMT, brachial FMD and CAC in the youngest population studied thus far (ie, young adults aged 24-39 years). The well-known link between the APOE phenotypes and serum lipids was clear but there was no association between ultrasound markers and APOE polymorphism. It seems obvious that APOE polymorphism is not an independent predictor of carotid IMT or other ultrasound markers of early atherosclerosis. The relation was not seen in young adults and the association found in other studies has disappeared after the inclusion of lipid parameters, suggesting that the association would at least, in part, be mediated through long-term effects of plasma lipids $3^{33}$ Debette and coworkers suggest that the APOE polymorphism is associated with carotid plaques but not, or only marginally, with carotid IMT 34 which would be in line with the finding that carotid plaques, but not carotid IMT, are associated with a parental history of premature death from coronary heart disease 43 Accordingly, hereditary factors (eg, APOE polymorphism) might be specifically involved in plaque formation but not necessarily with diffuse intima-media thickening. Also, mechanisms other than the effects of plasma lipids might be involved, as the association between APOE polymorphism and carotid plaques has been shown to be independent of lipid levels and because APOE also modulates platelet aggregation and lymphocyte proliferation, interacts with the extracellular matrix and protects against oxidative stress.44,45

A possible limitation of the present study might be the sensitivity of the measurements of carotid IMT, brachial FMD and CAC in evaluating early atherosclerotic changes. However, in the present cohort, established cardiovascular risk factors, such as dyslipidemia, elevated blood pressure, smoking, obesity and a family history of coronary heart disease, have been shown to be associated with these early markers of atherosclerosis, suggesting the validity of our methods! $12,38,46,47$

In conclusion, APOE polymorphism does not seem to be an independent genetic determinant of carotid IMT, brachial FMD or CAC, although APOE polymorphism itself is considered an important risk factor for coronary heart disease. The association found in many studies with elderly subjects might, at least in part, be mediated through the long-term effects of plasma lipids but, also, other APOE-related mechanisms might be involved in the development of atheroscle- 
rosis.

\section{Acknowledgments}

This study was financially supported by the Emil Aaltonen Foundation (T.L.), the Academy of Finland (grant no. 77841, 210283, 117941), the Social Insurance Institution of Finland, the Turku University Foundation, the Juho Vainio Foundation, the Finnish Foundation of Cardiovascular Research, the Finnish Cultural Foundation and the Tampere and Turku University Central Hospital Medical Funds.

\section{References}

1. Poredos P. Intima-media thickness: Indicator of cardiovascular risk and measure of the extent of atherosclerosis. Vasc Med 2004; 9: $46-$ 54.

2. Blacher J, Pannier B, Guerin AP, Marchais SJ, Safar ME, London GM. Carotid arterial stiffness as a predictor of cardiovascular and allcause mortality in end-stage renal disease. Hypertension 1998; 32: $570-574$.

3. Barenbrock M, Kosch M, Joster E, Kisters K, Rahn KH, Hausberg M. Reduced arterial distensibility is a predictor of cardiovascular disease in patients after renal transplantation. J Hypertens 2002; 20: $79-84$.

4. Humphries SE, Morgan L. Genetic risk factors for stroke and carotid atherosclerosis: Insights into pathophysiology from candidate gene approaches: Review. Lancet Neurol 2004; 3: 227-236.

5. Chambless LE, Heiss G, Folsom AR, Rosamond W, Szklo M, Sharret AR, et al. Association of coronary heart disease incidence with carotid arterial wall thickness and major risk factors: The Atherosclerosis Risk in Communities (ARIC) Study, 1987-1993. Am J Epidemiol 1997; 146: 483-494.

6. Bonetti PO, Lerman LO, Lerman A. Endothelial dysfunction: A marker of atherosclerotic risk. Arterioscler Thromb Vasc Biol 2003; 23: $168-175$.

7. Paul TK, Srinivasan SR, Wei C, Li S, Bhuiyan AR, Bond MG, et al. Cardiovascular risk profile of asymptomatic healthy young adults with increased femoral artery intima-media thickness: The Bogalusa Heart Study. Am J Med Sci 2005; 330: 105-110.

8. Leeson CP, Whincup PH, Cook DG, Mullen MJ, Donald AE, Seymour CA, et al. Cholesterol and arterial distensibility in the first decade of life: A population-based study. Circulation 2000; 101: $1533-1538$

9. Järvisalo MJ, Rönnemaa T, Volanen I, Kaitosaari T, Kallio K, Hartiala JJ, et al. Brachial artery dilatation responses in healthy children and adolescents. Am J Physiol Heart Circ Physiol 2002; 282: $\mathrm{H} 87-\mathrm{H} 92$.

10. Auggoun Y, Bonnet D, Sidi D, Girardet JP, Brucker E, Polak M, et al. Arterial mechanical changes in children with familial hypercholesterolemia. Arterioscler Thromb Vasc Biol 2000; 20: 2070-2075.

11. Kupari M, Hekali P, Keto P, Poutanen VP, Tikkanen MJ, Standerstkjöld-Nordenstam CG. Relation of aortic stiffness to factors modifying the risk of atherosclerosis in healthy people. Arterioscler Thromb 1994; 14: 386-394.

12. Juonala M, Järvisalo MJ, Mäki-Torkko N, Kähönen M, Viikari JSA, Raitakari OT. Risk factors identified in childhood and decreased carotid artery elasticity in adulthood: The Cardiovascular Risk in Young Finns Study. Circulation 2005; 112: 1486-1493.

13. Kirma C, Akcakoyun M, Esen AM, Barutcu I, Karakaya O, Saglam $\mathrm{M}$, et al. Relationship between endothelial function and coronary risk factors in patients with stable coronary artery disease. Circ J 2007; 71: $698-702$.

14. Bak S, Gaist D, Sindrup SH, Skytthe A, Christensen K. Genetic liability in stroke: A long-term follow-up study of Danish twins. Stroke 2002; 33: 769-774.

15. Barrett-Connor E, Khaw K. Family history of heart attack as an independent predictor of death due to cardiovascular disease. Circulation 1984; 69: 1065-1069.

16. Elosua R, Ordovas JM, Cupples LA, Fox CS, Polak JF, Wolf PA, et al. Association of APOE genotype with carotid atherosclerosis in men and women: The Framigham Heart Study. J Lipid Res 2004; 45: $1868-1875$

17. Lehtimäki T, Moilanen T, Viikari J, Åkerblom HK, Ehnholm C, Rönnemaa T, et al. Apolipoprotein E phenotypes in Finnish youths: A cross-sectional and 6-year follow-up study. J Lipid Res 1990; 31: 487-495.

18. Yamada Y. Identification of genetic factors and development of genetic risk diagnosis systems for cardiovascular diseases and stroke. Circ J 2006; 70: 1240-1248.
19. Ehnholm C, Lukka M, Kuusi T, Nikkilä E, Utermann G. Apolipoprotein E polymorphism in the Finnish population: Gene frequencies and relation to lipoprotein concentrations. J Lipid Res 1986; 27: 227-235.

20. Dallongeville J, Lussier-Cacan S, Davignon J. Modulation of plasma triglyceride levels by apoE phenotype: A meta-analysis. J Lipid Res 1992; 33: 447-454.

21. Wilson PWF, Schaefer EJ, Larson MG, Ordovas JM. Apolipoprotein $\mathrm{E}$ alleles and risk of coronary disease: A meta-analysis. Atheroscler Thromb Vasc Biol 1996; 16: 1250-1255.

22. Eichner JE, Kuller LH, Orchard TJ, Grandits GA, McCallum LM, Ferrell RE. Relationship of apolipoprotein E phenotype to myocardial infarction and mortality from coronary artery diasease. Am J Cardiol 1993; 71: 160-165.

23. Pei WD, Zhang YH, Sun YH, Gu YC, Wang YF, Zhang CY, et al. Apolipoprotein E polymorphism influences lipid phenotypes in Chinese families with familial combined hyperlipidemia. Circ J 2006; 70: $1606-1610$.

24. Fox CS, Polak JF, Chazaro I, Cupples A, Wolf PA, D'Agostino RA, et al. Genetic and environmental contributions to atherosclerosis phenotypes in men and women: Heritability of carotis intima-media thickness in the Framonghamn Heart Study. Stroke 2003; 34: $397-$ 401.

25. Zannad F, Sass C, Visvikis S. Environmental and genetic determinants of intima-media thickness of the carotid artery. Clin Exp Pharmacol Physiol 2001; 28: 1007-1010.

26. Beilby JP, Hunt CC, Palmer LJ, Chapman CM, Burley JP, McQuillan $\mathrm{BM}$, et al. Apolipoprotein E gene polymorphisms are associated with carotid plaque formation but not with intima-media wall thickness: Results from the Perth Carotid Ultrasound Disease Assessment Study (CUDAS). Stroke 2003; 34: 869-874.

27. Karvonen JH, Kauma H, Kervinen K, Ukkola O, Rantala M, Päivänsalo M, et al. Apolipoprotein E polymorphism affects carotid artery atherosclerosis in smoking hypertensive men. $J$ Hypertens 2002; 20: $2371-2378$

28. Ilveskoski E, Loimaala A, Mercury MF, Lehtimäki T, Pasanen M, Nenonen A, et al. Apolipoprotein E polymorphism and carotid intima media thickness in a random sample of middle-aged men. Atherosclerosis 2000; 153: 147-153.

29. Kogawa K, Nishizawa Y, Hosoi M, Kawagishi T, Maekawa K, Shoji $\mathrm{T}$, et al. Effect of polymorphism of apolipoprotein $\mathrm{E}$ and angiotensinconverting enzyme genes on arterial wall thickness. Diabetes 1997; 46: $682-687$.

30. Cattin L, Fisicaro M, Tonizzo M, Valenti M, Danek GM, Fonda M, et al. Polymorphism of the apolipoprotein E gene and early carotid atherosclerosis defined by ultrasonography in asymptomatic adults. Arterioscler Thromb Vasc Biol 1997; 17: 91-94.

31. Terry JG, Howard G, Mercuri M, Bond MG, Crouse JR $3^{\text {rd }}$. Apolipoprotein E polymorphism is associated with segment-specific extracranial carotid artery intima-media thickening. Stroke 1996; 27: $1755-1759$.

32. Fernandez-Miranda C, Aranda JL, Martin MA, Arenas J, Nunez V, Gomez de la Camara A. Apolipoprotein E polymorphism and carotid atherosclerosis in patients with coronary disease. Int J Cardiol 2004; 94: $209-212$.

33. Volcik KA, Barkley RA, Hutchinson RG, Mosley TH, Heiss G, Sharrett AR, et al. Apolipoprotein E polymorphism predict low density lipoprotein cholesterol levels and carotid artery wall thickness but not incident coronary heart disease in 12,491 ARIC study participants. Am J Epidemiol 2006; 164: 342-348.

34. Debette S, Lambert J-C, Gariépy J, Fievet N, Tzourio C, Dartigues J$F$, et al. New insights into the association of apolipoprotein E genetic variants with carotid plaques and intima-media thickness. Stroke 2006; 37: 2917-2923.

35. Haraki T, Takegoshi T, Kitoh C, Wakasugi T, Saga T, Hirai JI, et al. Carotid artery intima-media thickness and brachial artery flow-mediated vasodilation in asymptomatic Japanese male subjects amongst apolipoprotein E phenotypes. J Intern Med 2002; 252: 114-120.

36. Viiri LE, Raitakari OT, Huhtala H, Kähönen M, Rontu R, Juonala M, et al. Relations of APOE promoter polymorphisms to LDL cholesterol and markers of subclinical atherosclerosis in young adults. J Lipid Res 2006; 47: 1298-1306.

37. Åkerblom HK, Viikari J, Uhari M, Räsänen L, Byckling T, Louhivuori K, et al. Atherosclerosis precursors in Finnish children and adolescents. I: General description of the cross-sectional study of 1980 and an account of the children's and families' state of health. Acta Paediatr Scand Suppl 1985; 318: 49-63.

38. Raitakari OT, Juonala M, Kähönen M, Taittonen L, Laitinen T, MäkiTorkko N, et al. Cardiovascular risk factors in childhood as predictors of carotid artery intima-media thickness in adulthood: The Cardio- 
vascular Risk in Young Finns Study. JAMA 2003; 290: 2277-2283.

39. Juonala M, Viikari JSA, Laitinen T, Marniemi J, Helenius H, Rönnemaa $\mathrm{T}$, et al. Interrelations between brachial endothelial function and carotid intima-media thickness in young adults: The Cardiovascular Risk in Young Finns Study. Circulation 2004; 110: 2918 2923.

40. Menzel HJ, Utermann G. Apolipoprotein E phenotyping from serum by Western blotting. Electrophoresis 1986; 7: 492-495.

41. Kostner GM. Enzymatic determination of cholesterol in high-density lipoprotein fractions prepared by polyanion precipitation (Letter). Clin Chem 1976; 22: 695.

42. Friedewald WT, Levy RI, Fredrickson DS. Estimation of the concentration of low-density lipoprotein cholesterol in plasma without use of the preparative ultracentrifuge. Clin Chem 1972; 18: 499-502.

43. Zureik M, Touboul PJ, Bonithon-Kopp C, Courbon D, Ruelland I, Ducimetière P. Differential association of common carotid intimamedia thickness and carotid atherosclerotic plaques with parental history of premature death from coronary heart disease: The EVA study. Arterioscler Thromb Vasc Biol 1999; 19: 366-371.

44. Miyata M, Smith JD. Apolipoprotein E allele-specific antioxidant activity and effects on cytotoxicity by oxidative insults and betaamyloid peptides. Nat Genet 1996; 14: 55-61.

45. Mazzone T. Apolipoprotein E secretion by macrofages: Its potential physiological functions. Curr Opin Lipidol 1996; 7: 303-307.

46. Juonala M, Viikari JS, Räsänen L, Helenius H, Pietikäinen M, Raitakari OT. Young adults with family history of coronary heart disease have increased arterial vulnerability to metabolic risk factors: The Cardiovascular Risk in Young Finns Study. Arterioscler Thromb Vasc Biol 2006; 26: 1376-1382.

47. Juonala M, Viikari JS, Rönnemaa T, Helenius H, Taittonen L, Raitakari OT. Elevated blood pressure in adolescent boys predicts endothelial dysfunction: The cardiovascular risk in young Finns study. Hypertension 2006; 48: 424-430. 